\title{
Editorial
}

\section{A snapshot of the IDM's future}

\author{
Journal of Direct, Data and Digital Marketing Practice (2013) 14, 287-288.
}

doi:10.1057/dddmp.2013.31

We have spent the last 6 months undertaking a full review of our business in the context of a rapidly changing set of needs and challenges for the Marketing profession. We have evolved central driving missions and a way of simply articulating them to focus efforts, to identify change and to innovate how we define our relationships with all the main industry bodies under the Advertising Association umbrella - Incorporated Society of British Advertisers, Institute of Practitioners in Advertising, Direct Marketing Association, Marketing Agencies Association, Internet Advertising Bureau, British Interactive Media Association, Mobile Marketing Association, Public Relations Consultants Association and so on. This is vital because their members are our learners and we must be seen as close partners with them all in our dual missions articulated below.

In addition, of course, we must also remain competitive versus the many that now offer short course training across the plethora of topics covered. We continue to consider our range and quality of qualifications to be peerless, regardless of the competition.

A key finding - and crucial to address in the next stage of our development - has been the general lack of awareness and understanding of our brand, what we do (and especially what we do not), how we do it and what our underlying motivations are. We are the Institute of Direct and Digital Marketing - Europe's leading practitioner-led training and qualifications company that is all about improving marketing performance, not shareholder profit. We have membership propositions and an excellent career and personal development product.

We invest all our profits back into marketing via our education trust whose mission is to attract, inspire and educate the best young talent into the profession - the better we do, the more good we can do. This is delivered through over 40 universities, via a range of on-campus programmes that reach thousands of students and support hundreds of lecturers every year. Moreover, most importantly, we help hundreds of graduates into their first jobs.

We are not a direct or digital marketing trade body or industry association.

Other key themes emerging and now being planned for include: our own need to be open to any and all forms of collaboration, partnership and diversity (while keeping control of our product quality); the changing nature of recruitment and on-the-job training via internships, apprenticeships and postgrad schemes; value-based pricing; the requirement for 'commercial creativity' by modern marketers within technology-driven organizations; and, finally, sustainability in its widest form through corporate and social responsibility programmes, which are now under ever-closer scrutiny. In the next issue, I'll be taking more time and space to further articulate some of our developing plans and activities.

In closing, here are our dual missions:

- Attracting and inspiring the best young talent into marketing, driven by employability skills: Being the catalyst and conduit for our profession to attract the best talent; making marketing the go-to business career for the best young talent. 


\section{装. Editorial}

- Motivating and improving marketers throughout their careers: Improving marketing and business performance in measurable ways; being the first choice for improving practitioner skills throughout marketing careers.

There is a great deal going on that gives us tremendous optimism for the future of one of the UK's best and most learned networks: The IDM. Moreover, you are at the heart of it.

Mike Cornwell 